\title{
Current Surgical Treatment for Chronic Pancreatitis
}

\author{
Takayuki Aimoto, Eiji Uchida, Yoshiharu Nakamura, Kazuya Yamahatsu, \\ Akira Matsushita, Akira Katsuno, Kazumitsu Cho and Masao Kawamoto
}

Surgery for Organ Function and Biological Regulation, Graduate School of Medicine, Nippon Medical School

\begin{abstract}
Chronic pancreatitis (CP) is a painful, yet benign inflammatory process of the pancreas. Surgical management should be individualized because the pain is multifactorial and its mechanisms vary from patient to patient. Two main pathogenetic theories for the mechanisms of pain in CP have been proposed: the neurogenic theory and the theory of increased intraductal/intraparenchymal pressures. The latter theory is strongly supported by the good results of drainage procedures in the surgical management of $\mathrm{CP}$. Other possible contributing factors include pancreatic ischemia; a centrally sensitized pain state; and the development of complications, such as pseudocysts and stenosis of the duodenum or common bile duct. Common indications for surgery include intractable pain, suspicion of neoplasm, and complications that cannot be resolved with radiological or endoscopic treatments. Operative procedures have been historically classified into 4 categories: decompression procedures for diseased and obstructed pancreatic ducts; resection procedures for the proximal, distal, or total pancreas; denervation procedures of the pancreas; and hybrid procedures. Pancreaticoduodenectomy and pylorus-preserving pancreaticoduodenectomy, once the standard operations for patients with $\mathrm{CP}$, have been replaced by hybrid procedures, such as duodenum-preserving pancreatic head resection, the Frey procedure, and their variants. These procedures are safe and effective in providing long-term pain relief and in treating CP-related complications. Hybrid procedures should be the operations of choice for patients with CP.
\end{abstract}

(J Nippon Med Sch 2011; 78: 352-359)

Key words: chronic pancreatitis, mechanism of pain, surgical treatment, surgical indication, hybrid procedures

\section{Introduction}

Chronic pancreatitis (CP) is a progressive inflammatory disorder in which pancreatic secretory parenchyma is destroyed and replaced by fibrous tissue $^{1}$. The disease is characterized by recurrent episodes of intractable pain and other symptoms, such as diarrhea, steatorrhea, and diabetes mellitus, due to pancreatic exocrine and endocrine insufficiency ${ }^{1}$. In particular, attacks of severe pain lead to repeated hospitalization and lower quality of life $^{2}$. The medical treatment for CP-associated pain often fails because of narcotic dependency ${ }^{3}$. Therefore, intractable pain is the most common indication for surgical treatment in patients with

Correspondence to Takayuki Aimoto, MD, Department of Surgery, Nippon Medical School, 1-1-5 Sendagi, Bunkyoku, Tokyo 113-8603, Japan

E-mail: aimoto@nms.ac.jp

Journal Website (http://www.nms.ac.jp/jnms/) 
$\mathrm{CP}^{1,2}$.

Surgical approaches to the management of $\mathrm{CP}$ have made great progress over the past several decades because of a better understanding of the pathophysiology of $\mathrm{CP}$, the development of diagnostic methods, and improved outcomes of major pancreatic surgery ${ }^{3}$. The objectives of surgery are to relieve pain and to preserve pancreatic function ${ }^{1}$. Recently, surgical procedures have provided long-term pain relief and good postoperative quality of life along with lower rates of mortality and morbidity than with nonsurgical treatments ${ }^{3}$. Additionally, novel hybrid procedures, such as the Beger and Frey procedures have been introduced ${ }^{1}$. These procedures provide good pain relief and improve quality of life in patients with $\mathrm{CP}^{1.2}$. Therefore, this article provides an updated perspective on surgery for $\mathrm{CP}$.

\section{Mechanism of Pain in Patients with CP}

The cause of pain in $\mathrm{CP}$ is complicated and unclear. The neurophysiologic pain pathways involve the transmission of visceral afferent nociceptive information through the splanchnic nerves, sympathetic nervous system, spinal cord, and, ultimately, to the brain.

Demir et al. ${ }^{4}$ have summarized the recent findings about 3 possible mechanisms of pain in CP: peripheral nociception, peripheral pancreatic neuropathy and neuroplasticity, and central neuropathy and neuroplasticity. They concluded that pain in $\mathrm{CP}$ should be considered as neither solely peripheral nociceptive nor only peripheral pancreatic neuropathic, but rather as a mixed type of pain.

The following theories have been proposed to explain pain in $\mathrm{CP}$.

\section{Neurogenic Theory}

The neurogenic theory focuses on the peripheral pancreatic and central neuropathy and neuroplasticity described by Demir et $\mathrm{al}^{4}$. Several recent studies have revealed neural alterations: eosinophilic infiltration of intrapancreatic nerves in patients with painful $\mathrm{CP}^{5.6}$. Ultrastructural analysis of intrapancreatic nerves in $\mathrm{CP}$ have shown severe neural damage, such as disrupted perineurium, edematous neural contents, and penetration of inflammatory cells into the interior of nerves ${ }^{5.6}$. The damage to intrapancreatic nerves leads to numerous peripheral neuroplastic changes, such as hypertrophy and sprouting of intrapancreatic nerves ${ }^{5.6}$. Recent studies have demonstrated a key correlation between the extent of neural damage and the intensity and frequency of pain in patients with $\mathrm{CP}^{5.6}$. Repeated visceral afferent stimulation may result in a "centrally sensitized" pain state. This is a result of repeated stimulation of pain receptors as a consequence of tissue injury and visceral inflammation ${ }^{5.6}$. These peripheral nerve endings have increased sensitivity, a lower threshold to stimulation, and prolonged and enhanced responses to stimulation ${ }^{56}$.

\section{Interstitial and Intraductal Hypertension}

According to Demir et al., ductal hypertension due to constriction or calculi and increased intraparenchymal pressure as a result of fibrosis could activate the intrapancreatic nociceptors. Thus, increased pancreatic interstitial and ductal pressures cause a compartment syndrome that may cause pain in CP. Pancreatic ductal hypertension is thought to be caused by continuing exocrine secretion against a proximal obstruction due to single or multiple strictures or calculi or both ${ }^{5.6}$. Surgical treatment frequently relieves pain and decreases the pressure of a dilated pancreatic duct, although some studies have reported no significant relationship between pressure and pain or between pressure reduction and pain relief?.

\section{Inflammatory Mass}

Pain in $\mathrm{CP}$ is frequently present in patients with an inflammatory mass in the pancreatic head and can be effectively relieved by resection of the pancreatic head. The inflammatory mass may involve pancreatic and peripancreatic nerves and cause stenosis of the common bile duct or duodenum, all of which lead to pain ${ }^{6}$. The "pacemaker" of the pain of $\mathrm{CP}$ is generally believed to lie in the head of the pancreas. 


\section{Pseudocyst}

Acute exacerbations of CP may lead to pancreatic pseudocyst formation, which can cause intense pain by compressing adjacent organs ${ }^{6}$. Although a majority of pseudocysts disappear spontaneously, persistence or enlargement of pseudocysts may lead to persistent pain in patients with $\mathrm{CP}^{6}$.

\section{Indications for and Timing of Surgical Treatment}

\section{Surgical Indications}

Surgical treatment can be considered when conservative therapy or endoscopic intervention has failed. The common indications for surgery are intractable pain, suspicion of neoplasm, and unresolved stenosis of the duodenum or common bile duct $\mathrm{t}^{2.389}$. Other indications are complications that cannot be resolved with radiological or endoscopic treatment ${ }^{2,3.89}$. Currently, the acceptable indications for surgery are as follows.

1. Intractable pain

2. Suspicion of malignant neoplasm

3. Uncontrollable complications

a. Unresolved common bile duct stenosis

b. Pseudoaneurysms or vascular erosions not controlled with radiological intervention

c. Large pseudocysts not controlled with endoscopic treatment

\section{Timing of Surgical Interventions}

The aims of surgical treatment in patients with $\mathrm{CP}$ are to relieve intractable pain and to preserve pancreatic exocrine and endocrine functions as much as possible. Therefore, the timing of surgery in patients with $\mathrm{CP}$ should take these aims into account ${ }^{8.9}$.

Nealon et al. $^{10}$ compared the outcomes of conservative treatment and surgery and concluded that early operative drainage should be performed before irreversible functional or morphologic damage of the pancreas has occurred. Ihse et al. ${ }^{11}$ have also recommended that surgical treatment should be performed for patients with obstructive chronic pancreatitis or biliary pancreatitis before pancreatic insufficiency develops. Complications of adjacent organs should be treated surgically as soon

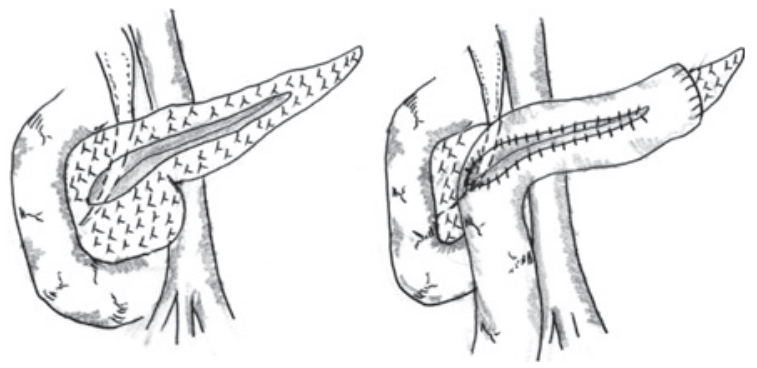

Fig. 1 Schematic illustration of the modified Puestow procedure

as they are diagnosed ${ }^{8}$.

\section{Selection of Surgical Procedures}

Operative procedures have historically been classified into 4 categories.

1. Decompression procedures of diseased and obstructed pancreatic ducts

2. Resection procedures of the proximal, distal, or total pancreas

3. Denervation procedures of the pancreas

4. Hybrid procedures

Surgical denervation, however, has been reported to be ineffective as a first-line treatment ${ }^{3.4}$. On the other hand, hybrid procedures combining resection of the pancreatic head with decompression have been introduced and have been proven to be as safe and effective as decompression or resection alone ${ }^{3,8,9}$.

\section{Decompression Procedures}

For patients with ductal dilation without a inflammatory mass in the pancreatic head, laterolateral pancreaticojejunostomy is an effective drainage operation.

In 1958, Puestow and Gillesby ${ }^{12}$ reported longitudinal decompression of the body and tail of the pancreas into a Roux limb of the jejunum. In 1960, Partington and Rochell ${ }^{13}$ described side-to-side longitudinal pancreaticojejunostomy without resection of the pancreatic tail, known as the modified Puestow procedure (Fig. 1). This procedure achieved short-term pain relief with low rates of morbidity and mortality in $61 \%$ to $91 \%$ of patients ${ }^{14-16}$. However, pain recurred within 3 to 5 years in up to $30 \%$ of patients ${ }^{14-16}$. The principal cause of failure of 
the Puestow operation is the lack of adequate decompression of the proximal ducts in the head of the pancreas ${ }^{17}$.

\section{Resection Procedures}

Proximal pancreatectomy

Pancreaticoduodenectomy (PD) has been considered an efficient means of relieving intractable pain and treating complications in patients with an inflammatory mass in the head of the pancreas. Recent studies of PD for the treatment of $\mathrm{CP}$ have found that short-term pain relief was achieved in $71 \%$ to $89 \%$ of patients $^{18}$. The morbidity rate, however, remains at about $40 \%$, and the mortality rate has been reduced to less than $5 \%$ at highvolume surgical centers ${ }^{19}$.

Pylorus-preserving PD $(\mathrm{PPPD})^{20}$ has been performed in an attempt to improve postoperative nutritional status. However, some studies have shown no significant nutritional differences between $\mathrm{PPPD}$ and $\mathrm{PD}^{21,22}$. A retrospective study by Jimenez et al. $^{19}$ of 72 patients undergoing $\mathrm{PD}$ or PPPD for $\mathrm{CP}$ found comparable rates of long-term pain relief, diabetes mellitus, and enzyme supplementation. In addition, an increased rates of delayed gastric emptying and marginal ulceration after PPPD have been reported ${ }^{23}$.

The most severe disadvantages of these procedures are the resection of the duodenum and the significant loss of pancreatic endocrine and exocrine function.

Total pancreatectomy

Total pancreatectomy (TP) should not be chosen as a first-line procedure. The indications for TP may be limited to failure of previous resection or severe, intractable pain with complete pancreatic insufficiency. In general, this procedure is thought to offer no better pain relief than does PD or PPPD for patients with $\mathrm{CP}$.

Recently, TP for $\mathrm{CP}$ has been increasingly performed with islet cell autotransplantation. The most severe morbidity after TP is brittle, insulindependent diabetes, and lethal episodes of hypoglycemia often occur in patients with apancreatic diabetes ${ }^{3,24}$. However, islet cell autotransplantation is contraindicated for $25 \%$ to
$30 \%$ of patients with CP because their islet cell function is already impaired because of severe diabetes, and, as a result, successful engraftment is difficult ${ }^{3}$. Further studies are needed before clinical application because several problems, such as islet unresponsiveness and apoptosis after isolation and engraftment, must first be solved ${ }^{3}$.

Distal pancreatectomy

Distal pancreatectomy (DP) has been used to treat patients with $\mathrm{CP}$ who have focal inflammatory changes, isolated duct stricture, or pseudocyst, localized to the body and tail.

The procedure is associated with a significant risk of symptomatic recurrence. Long-term pain relief is achieved in only $60 \%$ of patients, and completion pancreatectomy is required for pain relief in $13 \%$ of patients $^{25}$. In addition, pancreatic endocrine and exocrine insufficiency develops in half of patients who undergo $\mathrm{DP}^{3}$.

\section{Hybrid Procedures}

Duodenum-preserving pancreatic head resection (Fig. 2a)

In 1980, duodenum-preserving pancreatic head resection (DPPHR) was first described by Beger et $\mathrm{al}^{26}$, who reviewed the results of 380 DPPHR operations in $1997^{27}$. The neck of the pancreas is divided above the portal and superior mesenteric veins, and pancreatic tissue is excavated along the inner aspect of the duodenum. The common bile duct can be decompressed, if necessary. The reconstruction is performed by means of 2 pancreatojejunostomies with the Roux limb of the jejunum to drain the distal pancreas and to cover the remaining pancreatic head tissue and the decompressed bile duct. Longitudinal pancreaticojejunostomy can be added if the main duct in the body and tail of the pancreas is obstructed.

According to Beger et al. 50\% of patients required decompression of the common bile duct, and longitudinal pancreaticojejunostomy was performed in $10 \%$ to $15 \%$ of cases $^{28}$. In more than $80 \%$ of patients, pain relief was achieved, and endocrine and exocrine functions were also preserved $^{28}$. The incidence of new diabetes ranges from $8 \%$ to $21 \%$, 


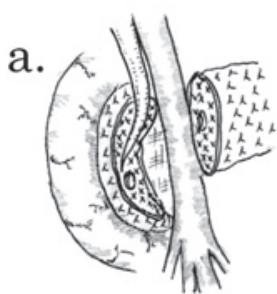

b.

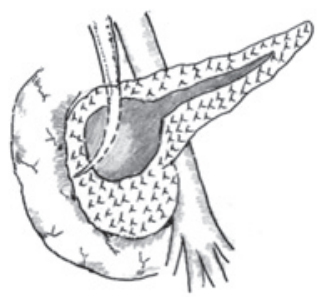

c.

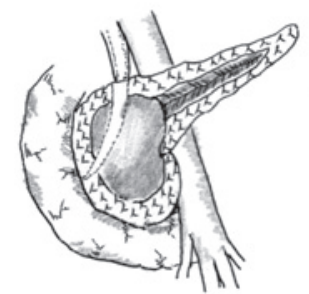

d.

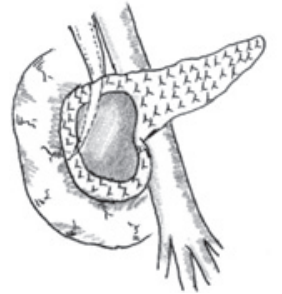

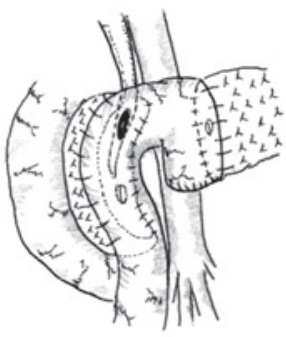
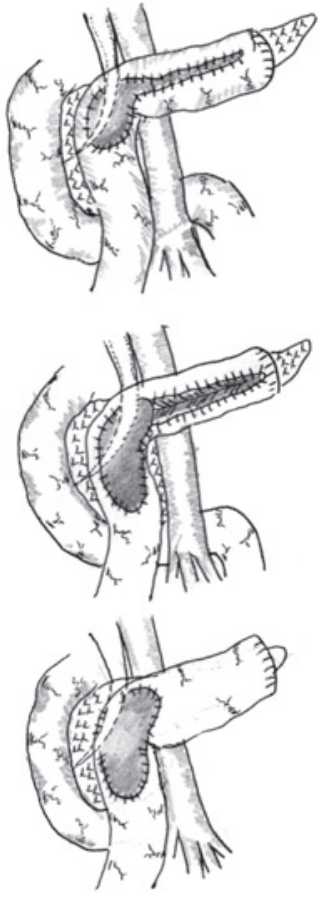

Fig. 2 Schematic illustrations of the hybrid procedures

a: Duodenal-preserving pancreatic head resection (DPPHR)

b: Frey procedure

c: Hamburg modification

d: Berne modification

and some patients show an improvement in glucose metabolism ${ }^{29}$. The DPPHR procedure is now widely accepted throughout the world.

Frey procedure (Fig. 2b)

The Frey procedure was described by Frey and Smith in $1987^{30}$. This operation is a modification of Beger procedure and the Partington-Rochelle procedure. The pancreatic neck above the portal and super mesenteric veins is preserved, which decreases the intraoperative bleeding. The excised head of the pancreas is linked to the longitudinally opened duct in the body and tail of the pancreas. To avoid penetrating the posterior capsule of the head, Frey and Amikura ${ }^{17}$ recommended that the posterior limit of resection should be the back wall of the opened duct of Wirsung. The locally excised head of the pancreas is covered with the opened Roux-en-Y limb of jejunum. This procedure is contraindicated for patients with a large inflammatory mass in the pancreatic head without stenosis of the left-sided pancreatic duct.

\section{Hamburg modification (Fig. 2c)}

Izbicki et al. ${ }^{31}$ introduced the Hamburg modification procedure, a modification of the Frey procedure. The procedure is the combination of the wider excavation of the pancreatic head and longitudinal V-shaped excision of the ventral aspect of the pancreas.

Small duct disease is the indication for this procedure. Yekebas et $\mathrm{al}^{32}$ have reported that mortality and morbidity rate were $0 \%$ and $19.6 \%$, respectively, and that $89 \%$ of patients were free of pain at follow-up.

\section{Berne modification (Fig. 2d)}

Farkas et al. $^{33}$ have reported organ-preserving pancreatic head resection, a coring out of the pancreatic head without lateral pancreaticojejunostomy. This approach was also described by Gloor et al. $^{34}$ as the "Berne modification," combining the advantages of the Beger and Frey procedures. However, if the duct is large or the mucosa of the duct is obviously inflamed, a long longitudinal pancreaticojejunostomy is appropriate for preventing recurrent stricture.

\section{Comparison of the Hybrid Procedures and}

\section{Resection Procedures}

Several large studies comparing hybrid procedures and resection procedures are shown in

\section{Table 1.}

PD or PPPD versus DPPHR

Two randomized prospective studies comparing DPPHR and PPPD or PD have clearly shown the benefits of DPPHR in terms of pain control and postoperative pancreatic function. Klempa et al. ${ }^{21}$ demonstrated in a study of 43 patients with a followup period of 3 to 5 years that those receiving DPPHR had better pain relief, a shorter hospital stay, and less postoperative pancreatic dysfunction than did those who underwent PD. Buchler et al. ${ }^{35}$ have found that after 6 months patients undergoing 


\section{Current Surgery for CP}

Table 1 Several studies comparing different procedures

\begin{tabular}{|c|c|c|c|c|c|c|c|c|c|}
\hline $\begin{array}{l}\text { Author } \\
\text { (ref. No.) }\end{array}$ & Year & $\begin{array}{r}\text { Study } \\
\text { (patient }\end{array}$ & $\begin{array}{l}\text { design } \\
\text { number) }\end{array}$ & Morbidity & Mortality & Pain relief & $\begin{array}{c}\text { New onset } \\
\text { DM }\end{array}$ & $\begin{array}{l}\text { QOL } \\
\text { score }\end{array}$ & $\begin{array}{l}\text { Follow- } \\
\text { up }\end{array}$ \\
\hline $\begin{array}{l}\text { Klempa } \\
21\end{array}$ & 1995 & $\mathrm{RCT}$ & $\begin{array}{c}\text { PD vs DPPHR } \\
\text { (21 vs } 22)\end{array}$ & $\mathrm{NC}$ & $0 \%$ vs $5 \%$ & $60 \%$ vs $70 \%$ & $38 \%$ vs $12 \%$ & $\mathrm{NA}$ & $5 \mathrm{Y}$ \\
\hline $\begin{array}{l}\text { Buchler } \\
35\end{array}$ & 1995 & $\mathrm{RCT}$ & $\begin{array}{l}\text { PPPD vs DPPHR } \\
\text { (20 vs } 20)\end{array}$ & $\mathrm{NC}$ & $0 \%$ vs $0 \%$ & $40 \%$ vs $75 \%$ & NA & NA & $6 \mathrm{M}$ \\
\hline $\begin{array}{l}\text { Aspelund } \\
36\end{array}$ & 2005 & A single-cohort & $\begin{array}{c}\text { PD vs DPPHR \& } \\
\text { Frey } \\
(7 \text { vs } 24)\end{array}$ & $\begin{array}{l}40 \% \text { vs } 25 \% \\
\quad \& 16 \%\end{array}$ & $6 \%$ vs $0 \%$ & NA & $25 \%$ vs $8 \%$ & NA & $3 \mathrm{Y}$ \\
\hline $\begin{array}{l}\text { Izbicki } \\
37\end{array}$ & 1998 & $\mathrm{RCT}$ & $\begin{array}{c}\text { PPPD vs Frey } \\
\text { (30 vs } 31)\end{array}$ & $53 \%$ vs $19 \%$ & $0 \%$ vs $3 \%$ & NS & NS & NA & $2 \mathrm{Y}$ \\
\hline $\begin{array}{l}\text { Strate } \\
38\end{array}$ & 2008 & $\mathrm{RCT}$ & $\begin{array}{l}\text { PPPD vs Frey } \\
\quad(30 \text { vs } 31)\end{array}$ & NS & NA & NS & $65 \%$ vs $61 \%$ & NA & $7 \mathrm{Y}$ \\
\hline $\begin{array}{l}\text { Farkas } \\
39\end{array}$ & 2006 & $\mathrm{RCT}$ & $\begin{array}{l}\text { PPPD vs Bern } \\
\text { (20 vs } 20)\end{array}$ & $40 \%$ vs $0 \%$ & $0 \%$ vs $0 \%$ & $90 \%$ vs $85 \%$ & NA & NA & $3 \mathrm{Y}$ \\
\hline $\begin{array}{l}\text { Izbicki } \\
41\end{array}$ & 1997 & $\mathrm{RCT}$ & $\begin{array}{c}\text { DPPHR vs Frey } \\
\text { (38 vs 36) }\end{array}$ & $32 \%$ vs $22 \%$ & $0 \%$ vs $0 \%$ & $89 \%$ vs $92 \%$ & $8 \%$ vs $6 \%$ & $\mathrm{NC}$ & $8.5 \mathrm{Y}$ \\
\hline $\begin{array}{l}\text { Riediger } \\
42\end{array}$ & 2007 & Nonrandomized & $\begin{array}{c}\text { PPPD vs DPPHR } \\
\text { or Frey } \\
\text { (90 vs } 42 \text { vs } 50)\end{array}$ & NS & NA & NS & NS & NA & $5 \mathrm{Y}$ \\
\hline $\begin{array}{l}\text { Koninger } \\
43\end{array}$ & 2008 & $\mathrm{RCT}$ & $\begin{array}{c}\text { Berne vs DPPHR } \\
\text { (33 vs } 32)\end{array}$ & $21 \%$ vs $20 \%$ & $0 \%$ vs $0 \%$ & NA & NA & $\begin{array}{c}71 \mathrm{vs} \\
66\end{array}$ & $2 Y$ \\
\hline
\end{tabular}

NS: not significant, NA: not available

DPPHR have better pain relief and better postoperative pancreatic function than do patients undergoing PPPD and have a similar morbidity rate. A retrospective study by Aspelund et $\mathrm{al}^{36}$ has shown that the rate of major complications is $25 \%$ after DPPHR and 40\% after PD.

Frey procedure versus PPPD

Izbicki et al..$^{37}$ performed a prospective randomized study of 61 patients to compare the Frey procedure and PPPD and found over a follow-up period of 2 years that patients who underwent the Frey procedure had a lower morbidity rate (19\%) and better quality of life scores $(71 \%)$ than did those who underwent PPPD (53\% and 43\%, respectively) and had a similar degree of pain relief. Strate et al. ${ }^{38}$ have recently found in a randomized trial of the Frey procedure and PPPD that rates of pain relief, pancreatic function, and survival were similar for both procedures after an average follow-up period of 7 years. However, the rates of new diabetes were $61 \%$ (Frey procedure) and 65\% (PPPD), both of which were twice as high as those before surgery.

Berne modification versus PPPD

Farkas et al. $^{39}$ examined 40 patients randomly assigned to undergo PPPD or the Berne modification and found that the Berne modification produced pain relief equal to that of PPPD but was also associated with shorter operating time, less intraoperative blood loss, a lower rate of postoperative morbidity, a shorter hospital stay, and a better quality of life than was PPPD. Anderson et al..$^{40}$ has also shown that the Berne modification produced good pain relief and no significant complications.

DPPHR versus the Frey procedure

Izbicki et al. $^{41}$ examined 74 patients randomly assigned to DPPHR or the Frey procedure with an average follow-up period of 8.5 years. This study showed no significant differences between the procedures in terms of pain intensity, mortality rate, exocrine or endocrine insufficiency, and global quality of life. Aspelund et $\mathrm{al}^{36}$ have found a lower incidence of new diabetes (8\%) for both DPPHR and the Frey procedure compared with PD (25\%). However, there were no significant differences in pain relief or complications between DPPHR and the Frey procedure.

On the other hand, long-term pancreatic insufficiency is closely associated with the 
progression of the underlying disease, because the late incidence of diabetes seems to be similar for DPPHR, the Frey procedure, and PPPD. Riediger et $\mathrm{al}^{42}$ have reported long-term outcomes in a nonrandomized series of 224 patients followed up for a median of 5 years after PPPD, DPPHR, or the Frey procedure. There was no significant difference in the rate of endocrine or exocrine dysfunction between the operations.

Berne modification versus DPPHR

Koninger et $\mathrm{al}^{43}$ have performed a randomized, controlled trial comparing the Berne method and DPPHR. They found that long-term pain relief and quality-of-life score did not differ significantly between the procedures.

\section{Conclusions}

The surgical technique must be adjusted for the pathomorphological changes of the pancreas. Both $\mathrm{PD}$ and PPPD, once the standard operations for patients with $\mathrm{CP}$, have been replaced by hybrid procedures, such as DPPHR, the Frey procedure, and their variants. These procedures are safe and effective in providing long-term pain relief and in treating CP-related complications. The hybrid procedures should be the operations of choice for patients with $\mathrm{CP}$. Although surgical treatment provides effective long-term pain-relief and improves quality of life, it does not stop decreases in either endocrine or exocrine function. Therefore, strategies to improve or maintain pancreatic endocrine and exocrine functions remain an important field of research.

\section{References}

1. Braganza JM, Lee SH, McCloy RF, McMahon MJ: Chronic pancreatitis. Lancet 2011; 377: 1184-1197.

2. Bachmann K, Mann O, Izbicki JR, Strate K: Chronic pancreatitis-a surgeon's view. Med Sci Monit 2008; 14: RA198-205.

3. Anderson DK, Frey CF: The Evolution of the Surgical Treatment of Chronic Pancreatitis. Ann Surg 2010; 251: 18-32.

4. Demir IE, Tieftrunk E, Maak M, Friess H, Ceyhan GO: Pain mechanisms in chronic pancreatitis: of a master and his fire. Langenbecks Arch Surg 2011; 396: 151-160.
5. Sakorafas GH, Tsiotou AG, Peros G: Mechanisms and natural history of pain in chronic pancreatitis: a surgical perspective. J Clin Gastroenterol 2007; 41: 689-699.

6. Chauhan S, Forsmark CE: Pain management in chronic pancreatitis: a treatment algorithm. Best Practice \& Research Clinical Gastroenterology 2010; 24: $323-335$.

7. Lieb JG II, Forsmark CE: Review article. Pain and chronic pancreatitis. Aliment Pharmacol Ther 2009; 29: 706-719.

8. Kai Bachmann K, Kutup A, Mann O, Yekebas E, Izbicki JR: Surgical treatment in chronic pancreatitis timing and type of procedure. Best Practice \& Research Clinical Gastroenterology 2010; 24: 299-310.

9. Strobel O, Büchler MW, Werner J: Surgical therapy of chronic pancreatitis: Indications, techniques and results. Int J Surg 2009; 7: 305-312.

10. Nealon WH, Thompson JC: Progressive loss of pancreatic function in chronic pancreatitis is delayed by main pancreatic duct decompression. Ann Surg 1993; 217: 458-468.

11. Ihse I, Borch K, Larsson J: Chronic pancreatitis: results of operations for relief of pain. World J Surg 1990; 14: 53-58.

12. Puestow CB, Gillesby WJ: Retrograde surgical drainage of pancreas for chronic relapsing pancreatitis. AMA Arch Surg 1958; 76: 898-907.

13. Partington PF, Rochelle RE: Modified Puestow procedure for retrograde drainage of the pancreatic duct. Ann Surg 1960; 152: 1037-1043.

14. Bradley EL III: Long-term results of pancreatojejunostomy in patients with chronic pancreatitis. Am J Surg 1987; 153: 207-213.

15. Mannell A, Adson MA, McIlrath DC, et al.: Surgical management of chronic pancreatitis: long-term results in 141 patients. Br J Surg 1988; 75: 467-472.

16. Taylor RH, Bagley FH, Braasch JW, et al.: Ductal drainage or resection for chronic pancreatitis. Am J Surg 1981; 141: 28-33.

17. Frey CF, Amikura K: Local resection of the head of the pancreas combined with longitudinal pancreaticojejunostomy in the management of patients with chronic pancreatitis. Ann Surg 1994; 220: 492-504.

18. Sakorafas GH, et al.: Pancreatoduodenectomy for chronic pancreatitis: long-term results in 105 patients. Arch Surg 2000; 135: 517-523.

19. Jimenez RE, et al.: Outcome of pancreaticoduodenectomy with pylorus preservation or with antrectomy in the treatment of chronic pancreatitis. Ann Surg 2000; 231: 293-300.

20. Traverso LW, Kozarek RA: Pancreatoduodenectomy for chronic pancreatitis: anatomic selection criteria and subsequent long-term outcome analysis. Ann Surg 1997; 226: 429-435.

21. Klempa I, Spatny M, Menzel J, et al.: Pancreatic function and quality of life after resection of the head of the pancreas in chronic pancreatitis. a prospective, randomized comparative study after duodenum preserving resection of the head of the pancreas versus Whipple's operation. Chirurg 1995; 66: 350-359.

22. Witzigmann $\mathrm{H}$, et al.: Quality of life in chronic pancreatitis: a prospective trial comparing classical 
Whipple procedure and duodenum-preserving pancreatic head resection. J Gastrointest Surg 2002; 6: $173-179$.

23. Muller MW, Friess H, Beger HG, et al.: Gastric emptying following pylorus preserving Whipple and duodenum-preserving pancreatic head resection in patients with chronic pancreatitis. Am J Surg 1997; 173: 257-263.

24. Cooper MJ, Williamson RC, Benjamin IS, et al: Total pancreatectomy for chronic pancreatitis. Br J Surg 1987; 74: 912-915.

25. Brancatisano RP, Williamson RC: Distal Pancreatectomy with or without splenctomy. In The Pancreas (Beger HG, Warshaw AL, Buchler MN, eds), 1998; pp 854, Blackwell-Science, London.

26. Beger HG, Witte C, Krautzberger W, et al. Experiences with duodenum sparing pancreas head resection in chronic pancreatitis in German. Chirurg 1980; 51: 303-307.

27. Buchler MW, Friess H, Bittner R, et al: Duodenumpreserving pancreatic head resection: long-term results. J Gastrointest Surg 1997; 1: 13-19.

28. Beger HG, Schlosser W, Friess HM, et al: Duodenum-preserving head resection in chronic pancreatitis changes the natural course of the disease: a single-center 26-year experience. Ann Surg 1999; 230: 512-519.

29. Malka D, Hammel P, Sauvanet A, et al.: Risk factors for diabetes mellitus in chronic pancreatitis. Gastroenterology 2000; 119: 1324-1332.

30. Frey CF, Smith GJ: Description and rationale of a new operation for chronic pancreatitis. Pancreas 1987; 2: 701-707.

31. Izbicki JR, Yekebas EF, Mann O: Chronic Pancreatitis. In Shackelford's Surgery of the Alimentary Tract (Yeo CJ, et al., ed), 2007; Saunders, New York, NY.

32. Yekebas EF, Bogoevski D, Honarpisheh $\mathrm{H}$, et al: Long-term follow-up in small duct chronic pancreatitis: A plea for extended drainage by "V shaped excision" of the anterior aspect of the pancreas. Ann Surg 2006; 244: 940-946.

33. Farkas G, Leindler L, Daroczi M, et al.: Organpreserving pancreatic head resection in chronic pancreatitis. Br J Surg 2003; 90: 29-32.

34. Gloor B, Friess H, Uhl W, et al.: A modified technique of the Beger and Frey procedure in patients with chronic pancreatitis. Dig Surg 2001; 18:
21-25.

35. Buchler MW, Friess H, Muller MW, Wheatley AM, Beger HG: Randomized trial of duodenum-preserving pancreatic head resection versus pylorus-preserving Whipple in chronic pancreatitis. Am J Surg 1995; 169: 65-69.

36. Aspelund G, Topazian MD, Lee JH, et al:: Improved outcomes for benign disease with limited pancreatic head resection. J Gastrointest Surg 2005; 9: 400-409.

37. Izbicki JR, Bloechle C, Broering DC, Knoefel WT, Kuechler T, Broelsch CE: Extended drainage versus resection in surgery for chronic pancreatitis: a prospective randomized trial comparing the longitudinal pancreaticojejunostomy combined with local pancreatic head excision with the pyloruspreserving pancreatoduodenectomy. Ann Surg 1998; 228: 771-779.

38. Strate T, Bachmann K, Busch P, et al.: Resection vs. drainage in treatment of chronic pancreatitis: longterm results of a randomized trial. Gastroenterology 2008; 134: 1406-1411.

39. Farkas G, Leindler L, Daroczi M, et al: Prospective randomised comparison of organ-preserving pancreatic head resection with pylorus-preserving pancreaticoduodenectomy. Langenbecks Arch Surg 2006; 391: 338-342.

40. Andersen DK, Topazian MD: Pancreatic head excavation: a variation on the theme of duodenumpreserving pancreatic head resection. Arch Surg 2004; 139: 375-379.

41. Izbicki JR, Bloechle C, Knoefel WT, et al: Duodenum-preserving resection of the head of the pancreas in chronic pancreatitis: a prospective, randomized trial. Ann Surg 1995; 221: 350-358.

42. Riediger $\mathrm{H}$, Adam U, Fischer E, et al.: Long-term outcome after resection for chronic pancreatitis in 224 patients. J Gastrointest Surg 2007; 11: 949-959.

43. Koninger J, Seiler CM, Sauerland S, et al: Duodenum-preserving pancreatic head resection-a randomized controlled trial comparing the original Beger procedure with the Berne modification (ISRCTN No. 50638764). Surgery 2008; 143: 490-498.

(Received,

July 14, 2011)

(Accepted, September 10, 2011) 